\title{
Improving Prognosis Estimation in Patients with Heart Failure and the Cardiorenal Syndrome
}

\author{
Husam M. Abdel-Qadir, ${ }^{1}$ Shaan Chugh, ${ }^{1}$ and Douglas S. Lee ${ }^{1,2,3}$ \\ ${ }^{1}$ Department of Medicine, University of Toronto, Toronto, ON, Canada M5G 2C4 \\ ${ }^{2}$ Institute for Clinical Evaluative Sciences, University of Toronto, G-106, 2075 Bayview Avenue, Toronto, ON, Canada M4N 3M5 \\ ${ }^{3}$ University Health Network and Toronto General Hospital, Toronto, ON, Canada
}

Correspondence should be addressed to Douglas S. Lee, dlee@ices.on.ca

Received 22 September 2010; Accepted 17 February 2011

Academic Editor: Mitchell H. Rosner

Copyright (C) 2011 Husam M. Abdel-Qadir et al. This is an open access article distributed under the Creative Commons Attribution License, which permits unrestricted use, distribution, and reproduction in any medium, provided the original work is properly cited.

\begin{abstract}
The coexistence of heart failure and renal dysfunction constitutes the "cardiorenal syndrome" which is increasingly recognized as a marker of poor prognosis. Patients with cardiorenal dysfunction constitute a large and heterogeneous group where individuals can have markedly different outcomes and disease courses. Thus, the determination of prognosis in this high risk group of patients may pose challenges for clinicians and for researchers alike. In this paper, we discuss the cardiorenal syndrome as it pertains to the patient with heart failure and considerations for further refining prognosis and outcomes in patients with heart failure and renal dysfunction. Conventional assessments of left ventricular function, renal clearance, and functional status can be complemented with identification of coexistent comorbidities, medication needs, microalbuminuria, anemia, biomarker levels, and pulmonary pressures to derive additional prognostic data that can aid management and provide future research directions for this challenging patient group.
\end{abstract}

\section{Introduction: The Scope of the Cardiorenal Syndrome}

Cardiac and renal dysfunctions often coexist. Approximately $70 \%$ of patients from community-based studies of heart failure (HF) have renal impairment, and 29\% have moderate to severe renal dysfunction [1]. Furthermore, a published series from the Mayo Clinic reported that the serum creatinine levels of HF patients have increased steadily from 1987 to 2002 [2]. An analysis of the Candesartan in Heart Failure: Assessment of Reduction in Mortality and Morbidity (CHARM) trials demonstrated that the prevalence of renal dysfunction was similar among patients with preserved ejection fraction and those with systolic dysfunction [3]. Moreover, a comparison of patients with ischemic HF and idiopathic dilated cardiomyopathy revealed that renal dysfunction was common in both patient groups [4]. This suggests that renal dysfunction in HF does not simply reflect the degree of left ventricular dysfunction or systemic atherosclerosis. While a universal, simple definition of the cardiorenal syndrome (CRS) remains elusive, a classification scheme based on the underlying precipitant of the CRS has been proposed [5] (see Table 1).

Renal function is one of the strongest prognostic factors among patients with HF. In a meta-analysis of approximately 78,000 patients with HF, Smith et al. [1] showed that renal impairment portended an increased risk of death, with an adjusted hazard ratio (HR) of 1.56 (95\% CI: $1.53-$ 1.60, $P<.001$ ). Hillege et al. [3] demonstrated that this risk was observed across the range of eGFRs below $60 \mathrm{~mL} / \mathrm{min} / 1.73 \mathrm{~m}^{2}$. The negative prognosis associated with a $10 \mathrm{~mL} / \mathrm{min} / 1.73 \mathrm{~m}^{2}$ decline in eGFR was comparable to that of a $5 \%$ decline in left ventricular ejection fraction (LVEF). Moreover, the prognostic value of eGFR was not significantly different among patients with reduced or preserved left ventricular ejection fraction. However, it has been 
TABLE 1: Classification scheme of the different types of the cardiorenal syndrome.

\begin{tabular}{lll}
\hline Type & Name & Description \\
\hline 1 & Acute CRS & Acute worsening of heart function leading to kidney injury and/or dysfunction \\
2 & Chronic CRS & Chronic abnormalities in heart function leading to kidney injury and/or dysfunction \\
3 & Acute renocardiac syndrome & Acute worsening of kidney function leading to heart injury and/or dysfunction \\
4 & Chronic renocardiac syndrome & Chronic kidney disease leading to heart injury, disease, and/or dysfunction \\
5 & Secondary CRS & Systemic conditions leading to simultaneous injury and/or dysfunction of heart and kidney \\
\hline
\end{tabular}

suggested that renal dysfunction might be associated with worse outcomes in patients with idiopathic cardiomyopathy, compared to those with an ischemic HF etiology [4].

Accordingly, patients with combined cardiac and renal dysfunction constitute a high risk group that is also large and heterogeneous, supporting the need for additional parameters to further delineate their risk of death and/or disease progression. The strongest prognostic information for these patients will continue to be derived from LVEF, estimates of renal function and New York Heart Association (NYHA) functional status. However, other clinical variables may play an increasingly important role in risk stratifying this large patient group with the ultimate aim of targeted interventions to improve outcomes.

\section{Measurement of Renal Dysfunction in Heart Failure}

Renal function can be estimated in several ways, yielding different estimates of eGFR. This becomes especially prominent among CHF patients whose body compositions might be markedly different than the chronic kidney disease (CKD) populations in whom these formulas were derived. Smilde et al. prospectively validated the accuracy and prognostic value of the Cockcroft-Gault (CG), Modification of Diet in Renal Disease (MDRD), and simplified MDRD (sMDRD) equations among patients with HF by comparison with the gold standard of ${ }^{125}$ I-iothalamate clearance [6]. All three formulas overestimated GFR in the lower ranges $\left(<35 \mathrm{~mL} / \mathrm{min} / 1.73 \mathrm{~m}^{2}\right)$, underestimated it in the upper ranges $\left(>65 \mathrm{~mL} / \mathrm{min} / 1.73 \mathrm{~m}^{2}\right)$, and functioned best in patients with NYHA classes III and IV. The MDRD was the most precise formula, while the CG was marginally more accurate. In comparison with directly measured GFR, the best prognostic value for cardiovascular outcomes came from creatinine clearance measurements using 24-hour urines and the MDRD equation, while the CG equation provided the least prognostic value. It has been reported that serum urea levels can also provide valuable prognostic information in CRS [7].

Accordingly, 24-hour urine collections should be periodically considered for determination of creatinine and urea clearance in $\mathrm{HF}$ patients with eGFR $<35 \mathrm{~mL} / \mathrm{min} / 1.73 \mathrm{~m}^{2}$, especially if heart transplantation or renal replacement therapy are being considered. Since creatinine is actively excreted into urine while urea is actively reabsorbed, measured creatinine clearance can significantly overestimate GFR in advanced CKD while urea clearances underestimate it. Thus, one method to estimate the GFR is to average both the creatinine and urea clearances, although this will require further study. There may be other potentially useful approaches to determine cardiorenal prognosis for HF patients including CG adjusted for body surface area [8], cystatin-C [9-14], and the Mayo eGFR formula [7].

\section{Identifying Patients at Risk for Worsening Renal Function Based on Comorbid Conditions}

A careful history of coexistent medical conditions can identify features that may increase the risk of subsequent renal compromise. Forman et al. examined risk factors for worsening renal function (WRF; defined as rise in serum creatinine of $>0.3 \mathrm{mg} / \mathrm{dL}$ ) among 1,004 consecutive patients admitted for a primary diagnosis of HF [15]. The highest risk of WRF was associated with elevated creatinine at admission. However, the presence of diabetes (adjusted hazard ratio [HR] 1.40) and a systolic blood pressure $>160 \mathrm{mmHg}$ (adjusted HR 1.37) were associated with a comparable risk of WRF to that of a history of prior HF (adjusted HR 1.31). A score derived from the regression model was useful in stratifying patient risk of WRF as shown in Table 2.

Other reported risk factors for WRF that can be identified at the time of admission for HF include

(i) rales/pulmonary edema [16, 17],

(ii) tachycardia [16],

(iii) female gender [16],

(iv) atrial fibrillation [17],

(v) peripheral arterial disease [17].

\section{Cardiorenal Syndrome and Medications}

The medications used by a patient can also provide insight into the stability of their cardiorenal axis. Furosemide is the one of most commonly prescribed medications among patients with HF, being used in over in $85 \%$ of outpatients at the time of hospital discharge [18]. Furosemide doses also frequently change among outpatients with HF [18]. In a study of 4,406 elderly patients discharged from an HF hospitalization, the prescription of higher furosemide doses ( $\geq 120 \mathrm{mg} /$ day) was more common among patients with higher creatinine levels, preadmission furosemide use, ischemic or valvular HF etiology, diabetes, atrial fibrillation, and COPD. Patients who were prescribed higher furosemide 
TABLE 2: Risk score developed by Forman et al. to predict worsening renal function [15].

\begin{tabular}{|c|c|c|c|c|}
\hline \multicolumn{3}{|c|}{ Risk factor } & \multicolumn{2}{|c|}{ Points } \\
\hline \multicolumn{3}{|c|}{ History of HF } & \multicolumn{2}{|c|}{1} \\
\hline \multicolumn{3}{|c|}{ Diabetes } & \multicolumn{2}{|c|}{1} \\
\hline \multicolumn{3}{|c|}{ Systolic blood pressure $>160 \mathrm{mmHg}$ at admission } & \multicolumn{2}{|c|}{1} \\
\hline \multicolumn{3}{|c|}{ Creatinine levels $\geq 1.5$ and $<2.5 \mathrm{mg} / \mathrm{dL}$} & \multicolumn{2}{|c|}{2} \\
\hline \multicolumn{3}{|c|}{ Creatinine levels $\geq 2.5 \mathrm{mg} / \mathrm{dL}$} & \multicolumn{2}{|c|}{3} \\
\hline Score & $n$ & $\%$ of patients with score & $\begin{array}{c}\% \text { of Patients with worsen } \\
\text { renal function }\end{array}$ & Relative risk \\
\hline 0 & 123 & 12.3 & 9.8 & Referent \\
\hline 1 & 257 & 25.6 & 18.7 & 1.9 \\
\hline 2 & 251 & 25 & 20.3 & 2.1 \\
\hline 3 & 155 & 15.4 & 30.3 & 3.1 \\
\hline $4+$ & 218 & 21.7 & 52.8 & 5.4 \\
\hline
\end{tabular}

doses were also more likely to exhibit hypotension, cardiomegaly, hyponatremia, and lower haemoglobin levels.

After extensive adjustment for covariates, exposure to higher furosemide dose was found to be predictive of death, hospitalization and renal dysfunction over five years of followup. Compared with the low-dose group $(\leq 59 \mathrm{mg}$ /day of furosemide), medium dose exposure (60-119 mg/day) was associated with increased mortality with an adjusted hazard ratio of 1.96 (95\% CI: 1.79-2.15) while high dose exposure conferred an even greater mortality risk with a hazard ratio of 3.00 (95\% CI: $2.72-3.31$; both $P<.001$ ). There was a comparable increase in the risk of death both in and out of hospital, raising the possibility of an increased risk of both pump failure and sudden death. These potential mechanisms of death were supported by the observation of a higher risk of arrhythmias with increasing furosemide doses. Moreover, there was a dose-dependent increase in hospitalization risk that was strongest for HF events, suggesting that the adverse outcomes are most specifically related to HF progression. Similarly, the risk of renal dysfunction rose with increasing furosemide exposure, such that medium dose and high dose furosemide were associated with adjusted hazard ratios of 1.56 (95\% CI: $1.38-1.76)$ and 2.16 (95\% CI: $1.88-2.49)$ compared to the low dose group [18]. These findings were concordant with prior observations [19-22], suggesting that furosemide dose may represent a valuable "pharmamarker" of cardiorenal dysfunction, whose utility is enhanced by its ubiquitous use and dynamic nature that may indicate changes in HF control over time.

Treatment with angiotensin converting enzyme (ACE) inhibitors or angiotensin-receptor blockers (ARBs) was associated with improved prognosis in this study of furosemide use. As a reflection of their heightened risk, the high-dose furosemide group was less likely to be treated with ACE inhibitors [18]. This mirrors the results of a retrospective analysis of the Minnesota Heart Survey where ACE inhibitor or ARB use was compared among 2,169 patients hospitalized with HF. There was progressively lower utilization of ACE inhibitors with declining eGFR. However, the in-hospital use of ACE inhibitors or ARBs was independently associated with significantly reduced 30-day mortality with an adjusted odds ratio of 0.45 (95\% CI: $0.28-0.59)$. Moreover, the discharge prescription of an ACE inhibitor or ARB was associated with a significant reduction in adjusted 1-year mortality with odds ratio of 0.72 (95\% CI: 0.58-0.91) [23]. However, there appears to be no mortality benefit associated with ACE inhibitor or ARB use among dialysis patients [23].

The most common concerns with ACE inhibitors and ARBs include worsening renal function and/or hyperkalemia [24]. However, patient subgroups with perceived contraindications to ACE inhibitors, including those with renal dysfunction, may tolerate high-dose ACE inhibitors well [25]. In a review of 12 randomized clinical trials of ACE inhibitors in patients with renal dysfunction (serum creatinine $>1.4 \mathrm{mg} / \mathrm{dL}$ ), acute increases in serum creatinine of up to $30 \%$ that stabilize within the first two months of ACE inhibitor therapy were strongly predictive of long-term preservation of renal function. This prompted the authors to recommend that ACE inhibitors should only be withheld when the creatinine rise exceeds $30 \%$ above baseline within the first 2 months of initiation or if hyperkalemia develops [26]. Moreover, an analysis from the Digitalis Investigation Group trial showed that among patients with perceived contraindications to ACE inhibitors (most commonly renal insufficiency), use of ACE inhibitors was associated with significant survival benefit at four-year followup [24].

\section{5. (Micro)albuminuria}

Albuminuria is a convergence point for several physiological derangements common in HF and CKD such as volume overload, hypertension, diabetes, and inflammation [2729]. The presence of proteinuria can serve as a marker of structural kidney damage [30-32] that can precede overt declines in renal function [33, 34]. Indeed, the presence of dipstick proteinuria with nearly normal renal function portends a higher risk of reaching end-stage renal disease than stage $4 \mathrm{CKD}$ in the absence of a positive dipstick test $[33,34]$. HF can also lead to albuminuria even in the absence of overt kidney dysfunction [35]. Nevertheless, albuminuria is more prevalent in HF patients with lower eGFR [35-37]. In the Valsartan in HF Trial, $5.6 \%$ of patients without CKD 
(i.e., those with eGFR $\geq 60 \mathrm{~mL} / \mathrm{min} / 1.73 \mathrm{~m}^{2}$ ) had dipstickpositive proteinuria compared to $10 \%$ of those with renal dysfunction [35]. In the Gruppo Italiano per lo Studio della Sopravvivenza nell'Infarto miocardico (GISSI-HF) trial, impaired renal function (eGFR $<60 \mathrm{~mL} / \mathrm{min} / 1.73 \mathrm{~m}^{2}$ ) was present in $30.1 \%$ of patients with normal urinary albumin excretion, $45.0 \%$ of those with microalbuminuria, and $53.0 \%$ of those with albuminuria [37]. It has been well reported that albuminuria is associated with worse outcomes in apparently healthy subjects as well as patients with cardiovascular disease, diabetes, and CKD [33, 34, 38-44].

The urinary albumin to creatinine ratio may further refine risk in patients with HF. In an analysis of 2,310 patients from the CHARM program [36], those with an elevated urinary albumin to creatinine ratio were older, had worse renal function, and had higher diabetes prevalence. They were also more likely to have been admitted for HF, and a higher proportion had NYHA functional class III or IV symptoms at randomization. The presence of microalbuminuria independently predicted a higher rate of adverse events, with hazard ratios for death of 1.62 (95\% CI: $1.32-1.99)$ for microalbuminuria and 1.76 (95\% CI: $1.32-$ 2.35) for macroalbuminuria compared to normoalbuminuria (both comparisons $P<.001$ ) [36]. Similar observations were reported in two subsequent studies [35,37], one of which demonstrated a progressive increase in the risk of death throughout the range of UACR's [37]. The proposed mechanisms of the increased risk associated with proteinuria are beyond the scope of this paper but have been reported elsewhere [45].

\section{Anemia}

Anemia is a common condition in both HF and CKD. Its estimated prevalence in patients with HF varies between $12-50 \%$ based on the cutoffs used [46-51]. In a metaanalysis of 153,180 HF patients from 34 studies, $37.2 \%$ were anemic [49]. The prevalence of anemia appears to be similar in patients with preserved and reduced left ventricular systolic function [51-53]. It is also a well-established feature of CKD, with anemia prevalence of $27 \%$ when eGFR is $\geq 60 \mathrm{~mL} / \mathrm{min} / 1.73 \mathrm{~m}^{2}$ to $75.5 \%$ in the presence of end-stage renal disease [54]. While the etiology in advanced kidney disease is believed to be mostly related to decreased erythropoietin production $[55,56]$, the anemia of HF is marked by elevated erythropoietin levels, although the elevation is often lower than expected for the degree of anemia $[57,58]$. This may be a consequence of the heightened inflammatory state that marks the HF syndrome [48, 57-59]. These factors may explain the inconsistent responses to erythropoietin stimulating agents in HF. Positive responses were observed in early, small trials but were not consistently replicated in larger trials with hard endpoints [60-63], including the TREAT trial which showed a higher stroke risk with darbepoetin alfa among patients with CKD and type 2 diabetes, approximately $1 / 3$ of which had HF [61].

HF and CKD also share other elements that could contribute to anemia such as iron deficiency, B12, folate and other nutritional deficiencies, and hemodilution [55-57, 60,
64-67]. In addition, both disease states commonly require the use of ACE inhibitors which decrease erythropoietin levels [68] and impair the breakdown of hematopoeisis inhibitors [58]. In a study of 59,772 adults with HF, the prevalence of anemia was $37 \%$ in patients with eGFR $>60 \mathrm{~mL} / \mathrm{min} / 1.73 \mathrm{~m}^{2}$ compared to $82 \%$ in those with stage 5 CKD [69]. Thus, HF and CKD may act synergistically to increase the prevalence of anemia. Additionally, anemic HF patients are more likely to be older with comorbid diabetes, lower blood pressure, higher diuretic use, higher NYHA functional class, reduced exercise capacity, worse quality of life, and increased neurohormonal activity [46-48, 50, 51, $57,60,62,65]$. The presence of anemia is also linked to a greater risk of death and hospitalization among patients with HF $[48,49,53,69]$. In the meta-analysis by Groenveld et al., $46.8 \%$ of anemic patients died compared with $29.5 \%$ of non-anemic patients among 153,180 patients followed for a minimum of 6 months [49]. Anemia was also associated with a hazard ratio of 1.43 for HF hospitalizations among 3,029 patients with NYHA class II to IV functional status and left ventricular ejection fraction $<35 \%$ [53].

The mortality risk associated with anemia appears to be similar among patients with preserved or reduced ejection fraction [52]. However, the mortality risk is nonlinear so that it is disproportionately weighted towards patients with more severe anemia $[48,53,69]$. Some reports have suggested that the relationship is better approximated by a J-shaped curve such that the risk of death may also be increased in patients with supranormal hemoglobin levels [53, 69]. Among patients with CKD, anemia is also predictive of development of end-stage renal disease [70], cardiovascular events [71], and death [70, 71]. The contribution of anemia to mortality risk is dependent on the degree of renal dysfunction, likely reflecting the dominant effect of renal dysfunction on mortality risk in the CRS. For example, in the study by Go et al., the presence of hemoglobin $<9.0 \mathrm{~g} / \mathrm{dL}$ was associated with a hazard ratio for death of 5.91 in patients with eGFR $>60 \mathrm{~mL} / \mathrm{min} / 1.73 \mathrm{~m}^{2}$, while the hazard ratio was 1.99 in patients with eGFR $<30 \mathrm{~mL} / \mathrm{min} / 1.73 \mathrm{~m}^{2}$ [69].

\section{Biomarkers}

The introduction of cardiac troponin assays revolutionized the management of acute coronary syndromes (ACS) by providing a powerful diagnostic and prognostic tool. With widespread use came the recognition that cardiac troponins can also serve as strong prognostic markers in HF and CKD outside the ACS setting. Serum troponin levels are elevated in $6-50 \%$ of patients with acute $\mathrm{HF}$ and have been linked to an increased risk of death and cardiovascular events among hospitalized and ambulatory patients with HF throughout the spectrum of the disease [72-76] in a doseresponse relationship [74]. In the setting of CKD, troponin measurements are frequently elevated in the absence of overt cardiac pathology [77-84], partly due to decreased renal clearance [85]. This CKD-associated elevation is more prominent for troponin $\mathrm{T}$ relative to troponin I $[77,78,83]$.

Troponin elevation in CKD reflects ongoing myocardial damage and necrosis and is strongly associated with diabetes, 
left ventricular dilatation, and impaired left ventricular systolic and diastolic function, without necessarily indicating the presence of severe coronary artery disease [86]. Elevations in troponin $\mathrm{T}$ have been more consistently linked to a poor prognosis in patients with CKD [77-84, 87-89], while studies conducted using troponin I have provided conflicting results $[77,78,83]$. In a meta-analysis of 3,931 patients from 28 studies, elevated troponin $\mathrm{T}(>0.1 \mathrm{ng} / \mathrm{mL}$ ) was associated with increased all-cause mortality with a relative risk of 2.64 (95\% CI: 2.17 to 3.20 ) in the setting of end-stage renal disease [78]. An important caveat is that blood measurements of troponin should be obtained just before dialysis [90].

B-type (brain) natriuretic peptide (BNP) and $\mathrm{N}$-terminal pro-BNP (NT-pro-BNP) have also emerged as valuable markers of HF severity [91]. Since they have different clearance kinetics, their levels are not interchangeable, although they often correlate with each other. In particular, the clearance of NT-proBNP appears to be more affected by renal dysfunction than that of BNP [92]. However, both natriuretic peptides are elevated in patients with advanced $\mathrm{CKD}$, suggesting that the elevation is multifactorial and not simply a result of decreased clearance [93-96]. Elevated levels of either natriuretic peptide are predictive of adverse outcomes among patients with HF. In a meta-analysis of 19 studies, each $100 \mathrm{pg} / \mathrm{mL}$ increase in BNP was associated with a 35\% increase in the relative risk of death [97]. There is less data on the prognostic value of NT-proBNP in unselected patients with HF but it appears to confer similar information to BNP [98]. Natriuretic peptides are also predictive of outcomes in patients with preserved systolic function, where the severity of diastolic dysfunction has been found to correlate with increased levels of both BNP and NT-proBNP $[99,100]$. The negative prognosis associated with natriuretic peptide elevation in CKD has been demonstrated in several studies [92].

The prognostic effects of these biomarkers are maintained in those with combined HF and renal disease. Their levels are still well correlated with left ventricular wall stress [101] and prognosis, although a higher NT-proBNP cutoff value is needed to separate patients with poor and intermediate prognosis. Bruch et al. compared the prognostic value of NT-proBNP in 183 ambulatory HF patients with CKD and 153 with eGFR $>60 \mathrm{~mL} / \mathrm{min} / 1.73 \mathrm{~m}^{2}$ and concluded that a cutoff value of $1,474 \mathrm{pg} / \mathrm{mL}$ best separated patients with poor and intermediate prognosis. Among patients with HF and CKD, cardiac event-free survival was $48 \%$ in patients above this cut-off compared with $93 \%$ in patients below it [102]. Anwarrudin et al. performed a similar analysis in patients presenting to the emergency department with HF, reaching the conclusion that NT-proBNP elevation was the strongest overall independent risk factor for 60-day mortality among those with eGFR $<60 \mathrm{~mL} / \mathrm{min} / 1.73 \mathrm{~m}^{2}$ with hazard ratio of 1.61 (95\% CI: 1.14-2.26). NT-proBNP also independently predicted HF hospitalization with a hazard ratio of 1.26 [103].

The use of natriuretic peptides as prognostic variables requires attention to a few caveats. Firstly, natriuretic peptide levels are lower in obese patients, although they do maintain good diagnostic and prognostic value when used with appropriately lowered cut-offs [104]. Natriuretic peptides are also less useful in evaluating HF due to causes other than left ventricular dysfunction such as mitral stenosis or pericardial disease $[91,105,106]$. Ideally, natriuretic peptide levels should be used as a continuous variable that takes into account the patient's baseline levels if available [91].

The use of biomarkers in this setting will undoubtedly continue to grow. Neutrophil gelatinase-associated lipocalin (NGAL) is an early marker of acute kidney injury with improved kinetics in comparison to traditional markers of renal clearance $[107,108]$, which may independently predict prognosis in CRS [109-113]. Similarly, Cystatin C is a small serine protease inhibitor which is also being touted as a more accurate and earlier marker of renal dysfunction [1014] and has already been shown to be a potent predictor of cardiovascular events and all-cause mortality in patients with and without overt cardiac or renal dysfunction [114120]. The increasing utility of such biomarkers has sparked growing interest in "multimarker" approaches to assess disease severity and prognosis in the setting of the CRS [121127]. However, it should be emphasized that biomarkers should be used as an adjunct to rather than a replacement for a full clinical assessment [128].

\section{Pulmonary Hypertension}

Pulmonary hypertension is a well-recognized consequence of HF, which constitutes Group 2 within the World Health Organization's classification of pulmonary hypertension [129]. Patients with CKD often have cardiac disease and pulmonary comorbidities such as sleep apnea that can lead to the development of pulmonary hypertension via increased left atrial pressure or chronic hypoxia in the absence of pulmonary arterial pathology [130-133]. The disproportionate prevalence of pulmonary hypertension in the absence of these causes within the CKD population is much less appreciated. In one study of patients with end-stage renal disease who did not have overt cardiac dysfunction or pulmonary disease, Doppler 2D echocardiography was used to estimate right ventricular systolic pressure 1-hour postdialysis, while at their dry weight. Of the study cohort, $39.7 \%$ had an estimated right ventricular systolic pressure $>35 \mathrm{mmHg}$, while $13.8 \%$ had values $>45 \mathrm{mmHg}$ [130]. This high prevalence of pulmonary hypertension was replicated in two other studies from different continents $[134,135]$. It is controversial whether pulmonary hypertension relates to the presence of end-stage renal disease itself or whether it is a consequence of dialysis, particularly via an arteriovenous fistula [130]. However, with reported prevalence of pulmonary hypertension as high as $39.1 \%$ in patients awaiting dialysis, and the improvement (and possible normalization) of right ventricular pressures among patients with end-stage renal disease after renal transplantation, evidence of an association is strengthened $[130,136]$.

The development of pulmonary hypertension in the presence of advanced CKD may be a harbinger of poor outcomes. In a study of 127 hemodialysis patients, 17 patients had pulmonary hypertension at dialysis outset, and 20 more developed elevated right-sided pressures after its 
initiation. After multivariate adjustment, the presence of pulmonary hypertension prior to dialysis was associated with a hazard ratio of 3.6 for death (95\% CI: 1.8-7.0) compared to patients without the condition at baseline. The development of new pulmonary hypertension after initiation of dialysis was associated with an adjusted hazard ratio for death of 2.1 (95\% CI: 1.1-4.3) [133]. It remains unclear why the presence of pulmonary hypertension increases risk of death so prominently in the end-stage renal disease population that already has a high rate of events. The presence of pulmonary hypertension may be associated with higher risk of adverse outcomes because it may reflect (a) advanced cardiac or respiratory disease, (b) greater severity of kidney disease-associated endothelial dysfunction secondary to nitric oxide and endothelin-1 derangements [136-139], (c) greater derangement of calcium metabolism with greater subsequent vascular calcification [135], (d) a state of high cardiac output in patients with arteriovenous fistulas [130, $135,136,140,141]$ which can induce high output HF, and (e) undiagnosed diastolic dysfunction, chronic volume overload, chronic hypoxia, or recurrent pulmonary embolic events $[134,135,142]$.

\section{Conclusion}

The development of the CRS is linked to a marked increase in the rates of death and morbidity compared to patients with either HF or CKD in isolation. However, there are multiple widely available noninvasive factors that can help the clinician estimate prognosis more accurately within this large and heterogeneous patient group. An assessment of left ventricular ejection fraction, renal function, and functional status remain paramount. The identification of co-existent diagnoses may indicate a high risk of worsening renal failure during HF hospitalization. The use of high furosemide doses or nonuse of ACE inhibitors or ARBs may identify patients with a tenuous cardiorenal axis or possibly suboptimal medical management. The presence of concomitant microalbuminuria or anemia may also provide clues to greater severity of cardiorenal compromise. The use of biomarkers such as BNP, troponin, NGAL, and cystatin$\mathrm{C}$ can provide additional information in monitoring this patient group. Finally, surveillance for pulmonary hypertension in patients with end-stage renal disease might allow for further refinement of prognosis in this patient group with its exceedingly high risk of death or morbidity.

\section{Conflict of Interests}

The authors have no conflicts of interest to declare.

\section{References}

[1] G. L. Smith, J. H. Lichtman, M. B. Bracken et al., "Renal impairment and outcomes in heart failure. systematic review and meta-analysis," Journal of the American College of Cardiology, vol. 47, no. 10, pp. 1987-1996, 2006.

[2] T. E. Owan, D. O. Hodge, R. M. Herges, S. J. Jacobsen, V. L. Roger, and M. M. Redfield, "Secular trends in renal dysfunction and outcomes in hospitalized heart failure patients," Journal of Cardiac Failure, vol. 12, no. 4, pp. 257262, 2006.

[3] H. L. Hillege, D. Nitsch, M. A. Pfeffer et al., "Renal function as a predictor of outcome in a broad spectrum of patients with heart failure," Circulation, vol. 113, no. 5, pp. 671-678, 2006.

[4] T. D. J. Smilde, H. L. Hillege, G. Navis, F. Boomsma, D. De Zeeuw, and D. J. Van Veldhuisen, "Impaired renal function in patients with ischemic and nonischemic chronic heart failure: association with neurohormonal activation and survival," American Heart Journal, vol. 148, no. 1, pp. 165172, 2004.

[5] C. Ronco, P. McCullough, S. D. Anker et al., "Cardio-renal syndromes: report from the consensus conference of the acute dialysis quality initiative," European Heart Journal, vol. 31, no. 6, pp. 703-711, 2010.

[6] T. D. J. Smilde, D. J. Van Veldhuisen, G. Navis, A. A. Voors, and H. L. Hillege, "Drawbacks and prognostic value of formulas estimating renal function in patients with chronic heart failure and systolic dysfunction," Circulation, vol. 114, no. 15, pp. 1572-1580, 2006.

[7] G. L. Smith, M. G. Shlipak, E. P. Havranek et al., "Serum urea nitrogen, creatinine, and estimators of renal function: mortality in older patients with cardiovascular disease," Archives of Internal Medicine, vol. 166, no. 10, pp. 1134-1142, 2006.

[8] Q. L. Zhang, H. Brenner, W. Koenig, and D. Rothenbacher, "Prognostic value of chronic kidney disease in patients with coronary heart disease: role of estimating equations," Atherosclerosis, vol. 211, no. 1, pp. 342-347, 2010.

[9] S. Manzano-Fernández, M. Boronat-Garcia, M. D. Albaladejo-Otón et al., "Complementary prognostic value of cystatin C, N-terminal Pro-B-Type natriuretic peptide and cardiac troponin $\mathrm{T}$ in patients with acute heart failure," American Journal of Cardiology, vol. 103, no. 12, pp. 1753-1759, 2009.

[10] C. White, A. Akbari, N. Hussain et al., "Estimating glomerular filtration rate in kidney transplantation: a comparison between serum creatinine and cystatin C-based methods," Journal of the American Society of Nephrology, vol. 16, no. 12, pp. 3763-3770, 2005.

[11] L. A. Stevens, J. Coresh, T. Greene, and A. S. Levey, "Assessing kidney function-measured and estimated glomerular filtration rate," New England Journal of Medicine, vol. 354, no. 23, pp. 2473-2483, 2006.

[12] B. A. Perkins, R. G. Nelson, B. E.P. Ostrander et al., "Detection of renal function decline in patients with diabetes and normal or elevated GFR by serial measurements of serum cystatin C concentration: results of a 4-year follow-up study," Journal of the American Society of Nephrology, vol. 16, no. 5, pp. 1404-1412, 2005.

[13] J. P. E. Lassus, M. S. Nieminen, K. Peuhkurinen et al., "Markers of renal function and acute kidney injury in acute heart failure: definitions and impact on outcomes of the cardiorenal syndrome," European Heart Journal, vol. 31, no. 22, pp. 2791-2798, 2010.

[14] J. F. Roos, J. Doust, S. E. Tett, and C. M. J. Kirkpatrick, "Diagnostic accuracy of cystatin C compared to serum creatinine for the estimation of renal dysfunction in adults and children-A meta-analysis," Clinical Biochemistry, vol. 40, no. 5-6, pp. 383-391, 2007.

[15] D. E. Forman, J. Butler, Y. Wang et al., "Incidence, predictors at admission, and impact of worsening renal function among 
patients hospitalized with heart failure," Journal of the American College of Cardiology, vol. 43, no. 1, pp. 61-67, 2004.

[16] H. M. Krumholz, Y. T. Chen, V. Vaccarino et al., "Correlates and impact on outcomes of worsening renal function in patients $\geq 65$ years of age with heart failure," American Journal of Cardiology, vol. 85, no. 9, pp. 1110-1113, 2000.

[17] M. R. Cowie, M. Komajda, T. Murray-Thomas, J. Underwood, and B. Ticho, "Prevalence and impact of worsening renal function in patients hospitalized with decompensated heart failure: results of the prospective outcomes study in heart failure (POSH)," European Heart Journal, vol. 27, no. 10, pp. 1216-1222, 2006.

[18] H. M. Abdel-Qadir, J. V. Tu, L. Yun, P. C. Austin, G. E. Newton, and D. S. Lee, "Diuretic dose and long-term outcomes in elderly patients with heart failure after hospitalization," American Heart Journal, vol. 160, no. 2, pp. 264-271, 2010.

[19] A. Ahmed, J. B. Young, T. E. Love, R. Levesque, and B. Pitt, "A propensity-matched study of the effects of chronic diuretic therapy on mortality and hospitalization in older adults with heart failure," International Journal of Cardiology, vol. 125, no. 2, pp. 246-253, 2008.

[20] M. Domanski, J. Norman, B. Pitt, M. Haigney, S. Hanlon, and E. Peyster, "Diuretic use, progressive heart failure, and death in patients in the studies of left ventricular dysfunction (SOLVD)," Journal of the American College of Cardiology, vol. 42, no. 4, pp. 705-708, 2003.

[21] S. Eshaghian, T. B. Horwich, and G. C. Fonarow, "Relation of loop diuretic dose to mortality in advanced heart failure," American Journal of Cardiology, vol. 97, no. 12, pp. 17591764, 2006.

[22] V. Hasselblad, S. W. Gattis, M. R. Shah et al., "Relation between dose of loop diuretics and outcomes in a heart failure population: Results of the ESCAPE Trial," European Journal of Heart Failure, vol. 9, no. 10, pp. 1064-1069, 2007.

[23] A. K. Berger, S. Duval, and C. Manske, "Angiotensinconverting enzyme inhibitors and angiotensin receptor blockers in patients with congestive heart failure and chronic kidney disease," American Heart Journal, vol. 153, pp. 10641073, 2007.

[24] A. Ahmed, R. M. Centor, M. T. Weaver, and G. J. Perry, "A propensity score analysis of the impact of angiotensinconverting enzyme inhibitors on long-term survival of older adults with heart failure and perceived contraindications," American Heart Journal, vol. 149, no. 4, pp. 737-743, 2005.

[25] B. M. Massie, P. W. Armstrong, J. G.F. Cleland et al., "Toleration of high doses of angiotensin-converting enzyme inhibitors in patients with chronic heart failure: esults from the ATLAS trial," Archives of Internal Medicine, vol. 161, no. 2, pp. 165-171, 2001.

[26] G. L. Bakris and M. R. Weir, "Angiotensin-converting enzyme inhibitor-associated elevations in serum creatinine: Is this a cause for concern?" Archives of Internal Medicine, vol. 160, no. 5, pp. 685-693, 2000.

[27] K. Damman, G. Navis, A. A. Voors et al., "Worsening renal function and prognosis in heart failure: systematic review and meta-analysis," Journal of Cardiac Failure, vol. 13, no. 8, pp. 599-608, 2007.

[28] A. Orea-Tejeda, E. Colín-Ramírez, T. Hernández-Gilsoul et al., "Microalbuminuria in systolic and diastolic chronic heart failure patients," Cardiology Journal, vol. 15, no. 2, pp. 143$149,2008$.

[29] W. D. Comper, L. M. Hilliard, D. J. Nikolic-Paterson, and L. M. Russo, "Disease-dependent mechanisms of albuminuria,"
American Journal of Physiology, vol. 295, no. 6, pp. F1589F1600, 2008.

[30] A. S. Levey, J. Coresh, E. Balk et al., "National kidney foundation practice guidelines for chronic kidney disease: evaluation, classification, and stratification," Annals of Internal Medicine, vol. 139, no. 2, pp. 137-147, 2003.

[31] G. Eknoyan, T. Hostetter, G. L. Bakris et al., "Proteinuria and other markers of chronic kidney disease: a position statement of the national kidney foundation (NKF) and the national institute of diabetes and digestive and kidney diseases (NIDDK)," American Journal of Kidney Diseases, vol. 42, no. 4, pp. 617-622, 2003.

[32] R. T. Gansevoort and P. E. De Jong, "The case for using albuminuria in staging chronic kidney disease," Journal of the American Society of Nephrology, vol. 20, no. 3, pp. 465-468, 2009.

[33] P. Ruggenenti, A. Perna, L. Mosconi, R. Pisoni, and G. Remuzzi, "Urinary protein excretion rate is the best independent predictor of ESRF in non-diabetic proteinuric chronic nephropathies," Kidney International, vol. 53, no. 5, pp. 1209 1216, 1998

[34] K. Iseki, K. Kinjo, C. Iseki, and S. Takishita, "Relationship between predicted creatinine clearance and proteinuria and the risk of developing ESRD in Okinawa, Japan," American Journal of Kidney Diseases, vol. 44, no. 5, pp. 806-814, 2004.

[35] I. S. Anand, K. Bishu, T. S. Rector, A. Ishani, M. A. Kuskowski, and J. N. Cohn, "Proteinuria, chronic kidney disease, and the effect of an angiotensin receptor blocker in addition to an angiotensin-converting enzyme inhibitor in patients with moderate to severe heart failure," Circulation, vol. 120, no. 16, pp. 1577-1584, 2009.

[36] C. E. Jackson, S. D. Solomon, H. C. Gerstein et al., "Albuminuria in chronic heart failure: prevalence and prognostic importance," The Lancet, vol. 374, no. 9689, pp. 543-550, 2009.

[37] S. Masson, R. Latini, V. Milani et al., "Prevalence and prognostic value of elevated urinary albumin excretion in patients with chronic heart failure data from the GISSI-Heart failure trial," Circulation: Heart Failure, vol. 3, no. 1, pp. 6572, 2010.

[38] J. Ärnlöv, J. C. Evans, J. B. Meigs et al., "Low-grade albuminuria and incidence of cardiovascular disease events in nonhypertensive and nondiabetic individuals: the framingham heart study," Circulation, vol. 112, no. 7, pp. 969-975, 2005.

[39] D. G. Warnock, P. Muntner, P. A. McCullough et al., "Kidney function, albuminuria, and all-cause mortality in the REGARDS (Reasons for Geographic and Racial Differences in Stroke) study," American Journal of Kidney Diseases, vol. 56, no. 5, pp. 861-871, 2010.

[40] H. C. Gerstein, J. F. E. Mann, Q. Yi et al., "Albuminuria and risk of cardiovascular events, death, and heart failure in diabetic and nondiabetic individuals," Journal of the American Medical Association, vol. 286, no. 4, pp. 421-426, 2001.

[41] K. Wachtell, H. Ibsen, M. H. Olsen et al., "Albuminuria and cardiovascular risk in hypertensive patients with left ventricular hypertrophy: the life study," Annals of Internal Medicine, vol. 139, no. 11, pp. 901-906, 2003.

[42] M. Tonelli, P. Jose, G. Curhan, F. Sacks, E. Braunwald, and M. Pfeffer, "Proteinuria, impaired kidney function, and adverse outcomes in people with coronary disease: analysis of a previously conducted randomised trial," British Medical Journal, vol. 332, no. 7555, pp. 1426-1429, 2006. 
[43] D. De Zeeuw, G. Remuzzi, H. H. Parving et al., "Albuminuria, a therapeutic target for cardiovascular protection in type 2 diabetic patients with nephropathy," Circulation, vol. 110, no. 8, pp. 921-927, 2004.

[44] D. De Zeeuw, G. Remuzzi, H. H. Parving et al., "Proteinuria, a target for renoprotection in patients with type 2 diabetic nephropathy: lessons from RENAAL," Kidney International, vol. 65, no. 6, pp. 2309-2320, 2004.

[45] K. Damman, H. L. Hillege, and D. J. van Veldhuisen, "Albuminuria in heart failure: a CHARMing new risk factor?" The Lancet, vol. 374, no. 9689, pp. 506-508, 2009.

[46] A. Al-Ahmad, W. M. Rand, G. Manjunath et al., "Reduced kidney function and anemia as risk factors for mortality in patients with left ventricular dysfunction," Journal of the American College of Cardiology, vol. 38, no. 4, pp. 955-962, 2001.

[47] I. Anand, J. J. V. McMurray, J. Whitmore et al., "Anemia and its relationship to clinical outcome in heart failure," Circulation, vol. 110, no. 2, pp. 149-154, 2004.

[48] I. S. Anand, M. A. Kuskowski, T. S. Rector et al., "Anemia and change in hemoglobin over time related to mortality and morbidity in patients with chronic heart failure: results from Val-HeFT," Circulation, vol. 112, no. 8, pp. 1121-1127, 2005.

[49] H. F. Groenveld, J. L. Januzzi, K. Damman et al., "Anemia and mortality in heart failure patients. A systematic review and meta-analysis," Journal of the American College of Cardiology, vol. 52, no. 10, pp. 818-827, 2008.

[50] T. B. Horwich, G. C. Fonarow, M. A. Hamilton, W. R. MacLellan, and J. Borenstein, "Anemia is associated with worse symptoms, greater impairment in functional capacity and a significant increase in mortality in patients with advanced heart failure," Journal of the American College of Cardiology, vol. 39, no. 11, pp. 1780-1786, 2002.

[51] E. O’Meara, T. Clayton, M. B. McEntegart et al., "Clinical correlates and consequences of anemia in a broad spectrum of patients with heart failure-results of the candesartan in heart failure: assessment of reduction in mortality and morbidity (CHARM) program," Circulation, vol. 113, no. 7, pp. 986-994, 2006.

[52] G. M. Felker, L. K. Shaw, W. G. Stough, and C. M. O'Connor, "Anemia in patients with heart failure and preserved systolic function," American Heart Journal, vol. 151, no. 2, pp. 457462, 2006.

[53] M. Komajda, S. D. Anker, A. Charlesworth et al., "The impact of new onset anaemia on morbidity and mortality in chronic heart failure: results from COMET," European Heart Journal, vol. 27, no. 12, pp. 1440-1446, 2006.

[54] W. McClellan, S. L. Aronoff, W. K. Bolton et al., "The prevalence of anemia in patients with chronic kidney disease," Current Medical Research and Opinion, vol. 20, no. 9, pp. 1501-1510, 2004.

[55] J. N. Basile, "Clinical considerations and practical recommendations for the primary care practitioner in the management of anemia of chronic kidney disease," Southern Medical Journal, vol. 100, no. 12, pp. 1200-1207, 2007.

[56] S. Nurko, "Anemia in chronic kidney disease: causes, diagnosis, treatment," Cleveland Clinic Journal of Medicine, vol. 73, no. 3, pp. 289-297, 2006.

[57] C. Opasich, M. Cazzola, L. Scelsi et al., "Blunted erythropoietin production and defective iron supply for erythropoiesis as major causes of anaemia in patients with chronic heart failure," European Heart Journal, vol. 26, no. 21, pp. 22322237, 2005.
[58] M. Volpe, C. Tritto, U. Testa et al., "Blood levels of erythropoietin in congestive heart failure and correlation with clinical, hemodynamic, and hormonal profiles," American Journal of Cardiology, vol. 74, no. 5, pp. 468-473, 1994.

[59] I. S. Anand, T. Rector, and A. Deswal, "Relationship between proinflammatory cytokines and anemia in heart failure," European Heart Journal, vol. 27, supplement 1, p. 485, 2006.

[60] I. S. Anand, "Anemia and chronic heart failure. implications and treatment options," Journal of the American College of Cardiology, vol. 52, no. 7, pp. 501-511, 2008.

[61] M. A. Pfeffer, E. A. Burdmann, C. Y. Chen et al., "A trial of darbepoetin alfa in type 2 diabetes and chronic kidney disease," New England Journal of Medicine, vol. 361, no. 21, pp. 2019-2032, 2009.

[62] A. Kazory and E. A. Ross, "Anemia: the point of convergence or divergence for kidney disease and heart failure?" Journal of the American College of Cardiology, vol. 53, no. 8, pp. 639647, 2009.

[63] F. Tehrani, P. Dhesi, D. Daneshvar et al., "Erythropoiesis stimulating agents in heart failure patients with anemia: a meta-analysis," Cardiovascular Drugs and Therapy, vol. 23, no. 6, pp. 511-518, 2009.

[64] J. M. Testani, J. Chen, B. D. McCauley, S. E. Kimmel, and R. P. Shannon, "Potential effects of aggressive decongestion during the treatment of decompensated heart failure on renal function and survival," Circulation, vol. 122, no. 3, pp. 265272, 2010.

[65] I. S. Anand, "Heart failure and anemia: mechanisms and pathophysiology," Heart Failure Reviews, vol. 13, no. 4, pp. 379-386, 2008.

[66] A. S. Androne, S. D. Katz, L. Lund et al., "Hemodilution is common in patients with advanced heart failure," Circulation, vol. 107, no. 2, pp. 226-229, 2003.

[67] G. Weiss and L. T. Goodnough, "Anemia of chronic disease," New England Journal of Medicine, vol. 352, no. 10, pp. 10111023, 2005.

[68] F. Fyhrquist, K. Karppinen, T. Honkanen, O. Saijonmaa, and K. Rosenlof, "High serum erythropoietin levels are normalized during treatment of congestive heart failure with enalapril," Journal of Internal Medicine, vol. 226, no. 4, pp. 257-260, 1989.

[69] A. S. Go, J. Yang, L. M. Ackerson et al., "Hemoglobin level, chronic kidney disease, and the risks of death and hospitalization in adults with chronic heart failure-the anemia in chronic heart failure: outcomes and resource utilization (ANCHOR) study," Circulation, vol. 113, no. 23, pp. 27132723, 2006.

[70] E. S. Johnson, M. L. Thorp, X. Yang, O. L. Charansonney, and D. H. Smith, "Predicting renal replacement therapy and mortality in CKD," American Journal of Kidney Diseases, vol. 50, no. 4, pp. 559-565, 2007.

[71] A. M. Walker, G. Schneider, J. Yeaw, B. Nordstrom, S. Robbins, and D. Pettitt, "Anemia as a predictor of cardiovascular events in patients with elevated serum creatinine," Journal of the American Society of Nephrology, vol. 17, no. 8, pp. 22932298, 2006.

[72] W. F. Peacock IV, T. De Marco, G. C. Fonarow et al., "Cardiac troponin and outcome in acute heart failure," New England Journal of Medicine, vol. 358, no. 20, pp. 2117-2126, 2008.

[73] D. Miani, C. Fresco, D. Lucci et al., "Clinical characteristics, management, and prognosis of octogenarians with acute heart failure admitted to cardiology wards: results from the Italian Survey on Acute Heart Failure," American Heart Journal, vol. 158, no. 1, pp. 126-132, 2009. 
[74] J. J. You, P. C. Austin, D. A. Alter, D. T. Ko, and J. V. Tu, "Relation between cardiac troponin I and mortality in acute decompensated heart failure," American Heart Journal, vol. 153, no. 4, pp. 462-470, 2007.

[75] M. P. Hudson, C. M. O'Connor, W. A. Gattis et al., "Implications of elevated cardiac troponin $t$ in ambulatory patients with heart failure: a prospective analysis," American Heart Journal, vol. 147, no. 3, pp. 546-552, 2004.

[76] N. Parenti, S. Bartolacci, F. Carle, and F. Angelo, "Cardiac troponin I as prognostic marker in heart failure patients discharged from emergency department," Internal and Emergency Medicine, vol. 3, no. 1, pp. 43-47, 2008.

[77] N. A. Abbas, R. I. John, M. C. Webb et al., "Cardiac troponins and renal function in nondialysis patients with chronic kidney disease," Clinical Chemistry, vol. 51, no. 11, pp. 20592066, 2005.

[78] N. A. Khan, B. R. Hemmelgarn, M. Tonelli, C. R. Thompson, and A. Levin, "Prognostic value of troponin T and I among asymptomatic patients with end-stage renal disease: a metaanalysis," Circulation, vol. 112, no. 20, pp. 3088-3096, 2005.

[79] D. S. Ooi and A. A. House, "Cardiac troponin T in hemodialyzed patients," Clinical Chemistry, vol. 44, no. 7, pp. 1410-1416, 1998.

[80] J. Dierkes, U. Domröse, S. Westphal et al., "Cardiac troponin $\mathrm{T}$ predicts mortality in patients end-stage renal disease," Circulation, vol. 102, no. 16, pp. 1964-1969, 2000.

[81] P. B. Deegan, M. E. Lafferty, A. Blumsohn, I. S. Henderson, and E. McGregor, "Prognostic value of troponin $\mathrm{T}$ in hemodialysis patients is independent of comorbidity," Kidney International, vol. 60, no. 6, pp. 2399-2405, 2001.

[82] B. Conway, M. McLaughlin, P. Sharpe, and J. Harty, "Use of cardiac troponin $\mathrm{T}$ in diagnosis and prognosis of cardiac events in patients on chronic haemodialysis," Nephrology Dialysis Transplantation, vol. 20, no. 12, pp. 2759-2764, 2005.

[83] F. S. Apple, M. M. Murakami, L. A. Pearce, and C. A. Herzog, "Predictive value of cardiac troponin I and T for subsequent death in end-stage renal disease," Circulation, vol. 106, no. 23, pp. 2941-2945, 2002.

[84] J. Ishii, M. Nomura, T. Okuma et al., "Risk stratification using serum concentrations of cardiac troponin $\mathrm{T}$ in patients with end-stage renal disease on chronic maintenance dialysis," Clinica Chimica Acta, vol. 312, no. 1-2, pp. 69-79, 2001.

[85] T. Tsutamoto, C. Kawahara, M. Yamaji et al., "Relationship between renal function and serum cardiac troponin $\mathrm{T}$ in patients with chronic heart failure," European Journal of Heart Failure, vol. 11, no. 7, pp. 653-658, 2009.

[86] R. Sharma, D. C. Gaze, D. Pellerin et al., "Cardiac structural and functional abnormalities in end stage renal disease patients with elevated cardiac troponin T," Heart, vol. 92, no. 6, pp. 804-809, 2006.

[87] M. Goicoechea, S. G. De Vinuesa, F. Gómez-Campderá, and J. Luño, "Predictive cardiovascular risk factors in patients with chronic kidney disease (CKD)," Kidney International, Supplement, vol. 67, no. 93, pp. S35-S38, 2005.

[88] M. Goicoechea, S. García De Vinuesa, F. Gómez-Campderá et al., "Clinical significance of cardiac troponin $\mathrm{T}$ levels in chronic kidney disease patients: predictive value for cardiovascular risk," American Journal of Kidney Diseases, vol. 43, no. 5, pp. 846-853, 2004.

[89] A. Orea-Tejeda, L. R. Sánchez-González, L. Castillo-Martínez et al., "Prognostic value of cardiac troponin $\mathrm{T}$ elevation is independent of renal function and clinical findings in heart failure patients," Cardiology Journal, vol. 17, no. 1, pp. 42-48, 2010.
[90] D. Wayand, H. Baum, G. Schatzle, J. Scharf, and D. Neumeier, "Cardiac troponin T and I in end-stage renal failure," Clinical Chemistry, vol. 46, no. 9, pp. 1345-1350, 2000.

[91] A. Maisel, C. Mueller, K. Adams et al., "State of the art: using natriuretic peptide levels in clinical practice," European Journal of Heart Failure, vol. 10, no. 9, pp. 824-839, 2008.

[92] A. Y.-M. Wang and K. N. Lai, "Use of cardiac biomarkers in end-stage renal disease," Journal of the American Society of Nephrology, vol. 19, no. 9, pp. 1643-1652, 2008.

[93] G. C. Fonarow, "The acute decompensated heart failure national registry (ADHERE): opportunities to improve care of patients hospitalized with acute decompensated heart failure," Reviews in Cardiovascular Medicine, vol. 4, supplement 7, pp. S21-S30, 2003.

[94] J. Hogenhuis, A. A. Voors, T. Jaarsma et al., "Anaemia and renal dysfunction are independently associated with BNP and NT-proBNP levels in patients with heart failure," European Journal of Heart Failure, vol. 9, no. 8, pp. 787-794, 2007.

[95] P. A. McCullough and K. R. Sandberg, "B-type natriuretic peptide and renal disease," Heart Failure Reviews, vol. 8, no. 4, pp. 355-358, 2003.

[96] P. A. McCullough, P. Duc, T. Omland et al., "B-type natriuretic peptide and renal function in the diagnosis of heart failure: an analysis from the breathing not properly multinational study," American Journal of Kidney Diseases, vol. 41, no. 3, pp. 571-579, 2003.

[97] J. A. Doust, E. Pietrzak, A. Dobson, and P. P. Glasziou, "How well does B-type natriuretic peptide predict death and cardiac events in patients with heart failure: systematic review," British Medical Journal, vol. 330, no. 7492, pp. 625627, 2005.

[98] S. Neuhold, M. Huelsmann, G. Strunk et al., "Comparison of copeptin, B-type natriuretic peptide, and amino-terminal pro-B-type natriuretic peptide in patients with chronic heart failure. prediction of death at different stages of the disease," Journal of the American College of Cardiology, vol. 52, no. 4, pp. 266-272, 2008.

[99] J. G. F. Cleland, J. Taylor, and M. Tendera, "Prognosis in heart failure with a normal ejection fraction," New England Journal of Medicine, vol. 357, no. 8, pp. 829-830, 2007.

[100] A. S. Maisel, J. McCord, R. M. Nowak et al., "Bedside Btype natriuretic peptide in the emergency diagnosis of heart failure with reduced or preserved ejection fraction: results from the breathing not properly multinational study," Journal of the American College of Cardiology, vol. 41, no. 11, pp. 2010-2017, 2003.

[101] S. Niizuma, Y. Iwanaga, T. Yahata et al., "Impact of left ventricular end-diastolic wall stress on plasma B-type natriuretic peptide in heart failure with chronic kidney disease and endstage renal disease," Clinical Chemistry, vol. 55, no. 7, pp. 1347-1353, 2009.

[102] C. Bruch, C. Fischer, J. Sindermann, J. Stypmann, G. Breithardt, and R. Gradaus, "Comparison of the prognostic usefulness of n-terminal pro-brain natriuretic peptide in patients with heart failure with versus without chronic kidney disease," American Journal of Cardiology, vol. 102, no. 4, pp. 469-474, 2008.

[103] S. Anwaruddin, D. M. Lloyd-Jones, A. Baggish et al., "Renal function, congestive heart failure, and amino-terminal probrain natriuretic peptide measurement: results from the ProBNP investigation of dyspnea in the emergency department (PRIDE) study," Journal of the American College of Cardiology, vol. 47, no. 1, pp. 91-97, 2006. 
[104] A. Bayes-Genis, D. M. Lloyd-Jones, R. R.J. Van Kimmenade et al., "Effect of body mass index on diagnostic and prognostic usefulness of amino-terminal pro-brain natriuretic peptide in patients with acute dyspnea," Archives of Internal Medicine, vol. 167, no. 4, pp. 400-407, 2007.

[105] L. Babuin, J. R. Alegria, J. K. Oh, R. A. Nishimura, and A. S. Jaffe, "Brain natriuretic peptide levels in constrictive pericarditis and restrictive cardiomyopathy," Journal of the American College of Cardiology, vol. 47, no. 7, pp. 1489-1491, 2006.

[106] F. S. Leya, D. Arab, D. Joyal et al., "The efficacy of brain natriuretic peptide levels in differentiating constrictive pericarditis from restrictive cardiomyopathy," Journal of the American College of Cardiology, vol. 45, no. 11, pp. 19001902, 2005.

[107] E. D. Siew, L. B. Ware, T. Gebretsadik et al., "Urine neutrophil gelatinase-associated lipocalin moderately predicts acute kidney injury in critically ill adults," Journal of the American Society of Nephrology, vol. 20, no. 8, pp. 1823-1832, 2009.

[108] J. Mishra, Q. Ma, A. Prada et al., "Identification of neutrophil gelatinase-associated lipocalin as a novel early urinary biomarker for ischemic renal injury," Journal of the American Society of Nephrology, vol. 14, no. 10, pp. 2534-2543, 2003.

[109] A. Yndestad, L. Landrø, T. Ueland et al., "Increased systemic and myocardial expression of neutrophil gelatinaseassociated lipocalin in clinical and experimental heart failure," European Heart Journal, vol. 30, no. 10, pp. 1229-1236, 2009.

[110] A. Aghel, K. Shrestha, W. Mullens, A. Borowski, and W. H. Tang, "Serum neutrophil gelatinase-associated lipocalin (NGAL) in predicting worsening renal function in acute decompensated heart failure," Journal of Cardiac Failure, vol. 16, pp. 49-54, 2010.

[111] D. Bolignano, G. Coppolino, A. Lacquaniti, and M. Buemi, "From kidney to cardiovascular diseases: NGAL as a biomarker beyond the confines of nephrology," the European Society for Clinical Investigation, vol. 40, pp. 273-276, 2010.

[112] K. Damman, D. J. Van Veldhuisen, G. Navis et al., "Tubular damage in chronic systolic heart failure is associated with reduced survival independent of glomerular filtration rate," Heart, vol. 96, no. 16, pp. 1297-1302, 2010.

[113] M. Alvelos, R. Pimentel, E. Pinho et al., "Neutrophil gelatinase-associated lipocalin in the diagnosirs of type 1 cardio-renal syndrome in the general ward," Clinical Journal of the American Society of Nephrology, vol. 6, no. 3, pp. 476$481,2011$.

[114] T. Jernberg, B. Lindahl, S. James, A. Larsson, L. O. Hansson, and L. Wallentin, "Cystatin C: a novel predictor of outcome in suspected or confirmed non-ST-elevation acute coronary syndrome," Circulation, vol. 110, no. 16, pp. 2342-2348, 2004.

[115] M. G. Shlipak, R. Katz, L. F. Fried et al., "Cystatin-C and mortality in elderly persons with heart failure," Journal of the American College of Cardiology, vol. 45, pp. 268-271, 2005.

[116] M. G. Shlipak, M. J. Sarnak, R. Katz et al., "Cystatin C and the risk of death and cardiovascular events among elderly persons," New England Journal of Medicine, vol. 352, no. 20, pp. 2049-2060, 2005.

[117] J. H. Ix, M. G. Shlipak, G. M. Chertow, and M. A. Whooley, "Association of cystatin C with mortality, cardiovascular events, and incident heart failure among persons with coronary heart disease: data from the heart and soul study," Circulation, vol. 115, no. 2, pp. 173-179, 2007.
[118] J. Lassus, V. P. Harjola, R. Sund et al., "Prognostic value of cystatin $\mathrm{C}$ in acute heart failure in relation to other markers of renal function and NT-proBNP," European Heart Journal, vol. 28, no. 15, pp. 1841-1847, 2007.

[119] T. Keller, C. M. Messow, E. Lubos et al., "Cystatin C and cardiovascular mortality in patients with coronary artery disease and normal or mildly reduced kidney function: results from the atheroGene study," European Heart Journal, vol. 30, no. 3, pp. 314-320, 2009.

[120] C.-K. Wu, J.-W. Lin, J. L. Caffrey, M.-H. Chang, J.-J. Hwang, and Y.-S. Lin, "Cystatin C and long-term mortality among subjects with normal creatinine-based estimated glomerular filtration rates: NHANES III (Third National Health and Nutrition Examination Survey)," Journal of the American College of Cardiology, vol. 56, no. 23, pp. 1930-1936, 2010.

[121] S. Manzano-Fernández, M. Boronat-Garcia, M. D. Albaladejo-Otón et al., "Complementary prognostic value of cystatin $\mathrm{C}$, N-terminal pro-B-type natriuretic peptide and cardiac troponin $\mathrm{T}$ in patients with acute heart failure," American Journal of Cardiology, vol. 103, no. 12, pp. 1753-1759, 2009.

[122] B. Zethelius, L. Berglund, J. Sundström et al., "Use of multiple biomarkers to improve the prediction of death from cardiovascular causes," New England Journal of Medicine, vol. 358, no. 20, pp. 2107-2116, 2008.

[123] O. Melander, C. Newton-Cheh, P. Almgren et al., "Novel and conventional biomarkers for prediction of incident cardiovascular events in the community," Journal of the American Medical Association, vol. 302, no. 1, pp. 49-57, 2009.

[124] R. B. Schnabel, A. Schulz, C. M. Messow et al., "Multiple marker approach to risk stratification in patients with stable coronary artery disease," European Heart Journal, vol. 31, no. 24, pp. 3024-3031, 2010.

[125] J. G. Smith, C. Newton-Cheh, P. Almgren et al., "Assessment of conventional cardiovascular risk factors and multiple biomarkers for the prediction of incident heart failure and atrial fibrillation," Journal of the American College of Cardiology, vol. 56, no. 21, pp. 1712-1719, 2010.

[126] S. M. Dunlay, Y. Gerber, S. A. Weston, J. M. Killian, M. M. Redfield, and V. L. Roger, "Prognostic value of biomarkers in heart failure application of novel methods in the community," Circulation: Heart Failure, vol. 2, no. 5, pp. 393-400, 2009.

[127] F. S. Apple, M. A.M. Murakami, L. A. Pearce, and C. A. Herzog, "Multi-biomarker risk stratification of N-terminal pro-B-type natriuretic peptide, high-sensitivity C-reactive protein, and cardiac troponin $\mathrm{T}$ and $\mathrm{I}$ in end-stage renal disease for all-cause death," Clinical Chemistry, vol. 50, no. 12, pp. 2279-2285, 2004.

[128] D. S. Lee and J. V. Tu, "Are multiple biomarker testing strategies ready for prime time in heart failure?" Circulation: Heart Failure, vol. 2, no. 5, pp. 387-388, 2009.

[129] G. Simonneau, I. M. Robbins, M. Beghetti et al., "Updated clinical classification of pulmonary hypertension," Journal of the American College of Cardiology, vol. 54, supplement 1, pp. S43-S54, 2009.

[130] M. Yigla, F. Nakhoul, A. Sabag et al., "Pulmonary hypertension in patients with end-stage renal disease," Chest, vol. 123, no. 5, pp. 1577-1582, 2003.

[131] J. J. Sim, S. A. Rasgon, D. A. Kujubu et al., "Sleep apnea in early and advanced chronic kidney disease," Chest, vol. 135, no. 3, pp. 710-716, 2009. 
[132] J. J. Sim, S. A. Rasgon, and S. F. Derose, "Sleep apnea and hypertension: prevalence in chronic kidney disease," Journal of Clinical Hypertension, vol. 9, no. 11, pp. 837-841, 2007.

[133] M. Yigla, O. Fruchter, D. Aharonson et al., "Pulmonary hypertension is an independent predictor of mortality in hemodialysis patients," Kidney International, vol. 75, no. 9, pp. 969-975, 2009.

[134] R. J. Harp, S. W. Stavropoulos, A. G. Wasserstein, and T. W. I. Clark, "Pulmonary hypertension among end-stage renal failure patients following hemodialysis access thrombectomy," CardioVascular and Interventional Radiology, vol. 28, no. 1, pp. 17-22, 2005.

[135] Y. Havlucu, S. Kursat, C. Ekmekci et al., "Pulmonary hypertension in patients with chronic renal failure," Respiration, vol. 74, no. 5, pp. 503-510, 2007.

[136] F. Nakhoul, M. Yigla, R. Gilman, S. A. Reisner, and Z. Abassi, "The pathogenesis of pulmonary hypertension in haemodialysis patients via arterio-venous access," Nephrology Dialysis Transplantation, vol. 20, no. 8, pp. 1686-1692, 2005.

[137] S. T. Morris and A. G. Jardine, "The vascular endothelium in chronic renal failure," Journal of Nephrology, vol. 13, no. 2, pp. 96-105, 2000.

[138] J. Thambyrajah, M. J. Landray, F. J. McGlynn, H. J. Jones, D. C. Wheeler, and J. N. Townend, "Abnormalities of endothelial function in patients with predialysis renal failure," Heart, vol. 83, no. 2, pp. 205-209, 2000.

[139] N. D. Vaziri, "Effect of chronic renal failure on nitric oxide metabolism," American Journal of Kidney Diseases, vol. 38, no. 4, supplement 1, pp. S74-S79, 2001.

[140] M. R. Clarkson, L. Giblin, A. Brown, D. Little, and J. Donohoe, "Reversal of pulmonary hypertension after ligation of a brachiocephalic arteriovenous fistula," American Journal of Kidney Diseases, vol. 40, no. 3, p. E8, 2002.

[141] M. Yigla, Z. Abassi, S. A. Reisner, and F. Nakhoul, "Pulmonary hypertension in hemodialysis patients: an unrecognized threat," Seminars in Dialysis, vol. 19, no. 5, pp. 353-357, 2006.

[142] M. Barak and Y. Katz, "Microbubbles: pathophysiology and clinical implications," Chest, vol. 128, pp. 2918-2932, 2005. 


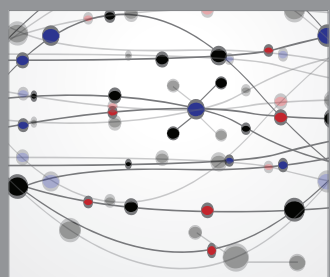

The Scientific World Journal
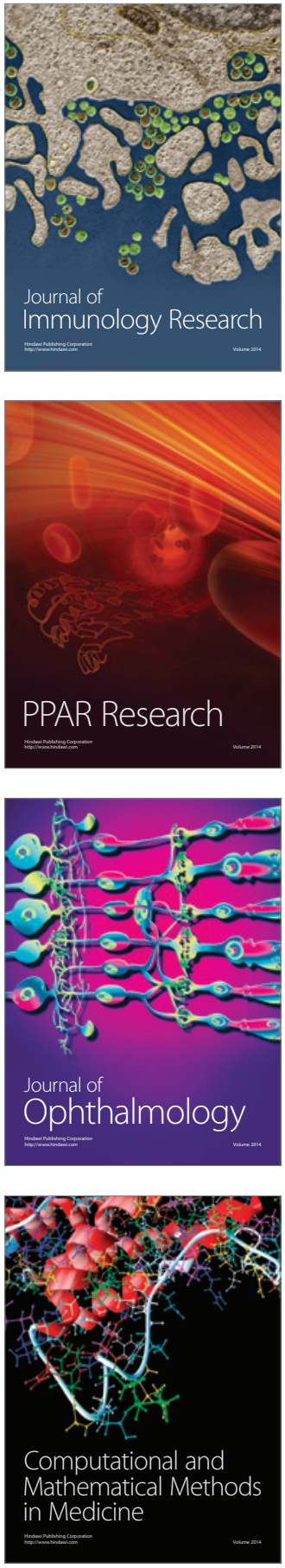

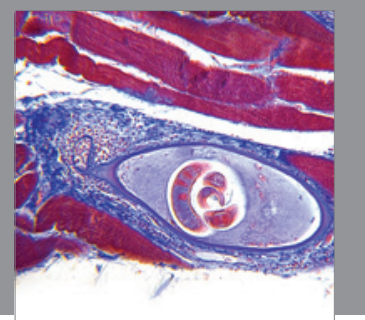

Gastroenterology

Research and Practice
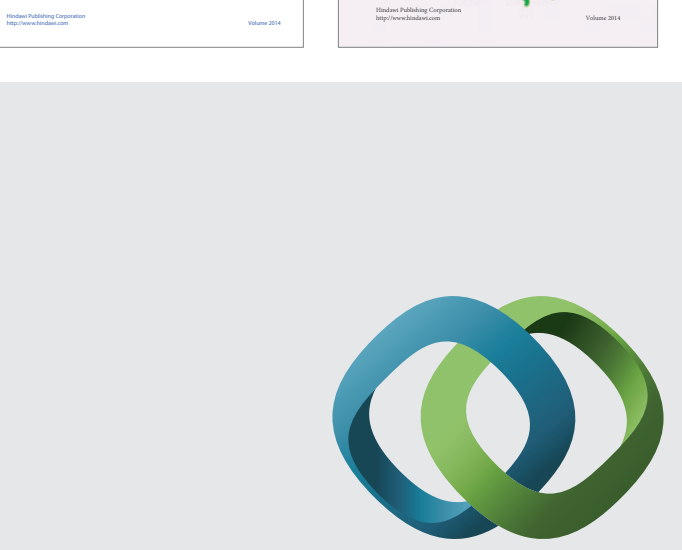

\section{Hindawi}

Submit your manuscripts at

http://www.hindawi.com
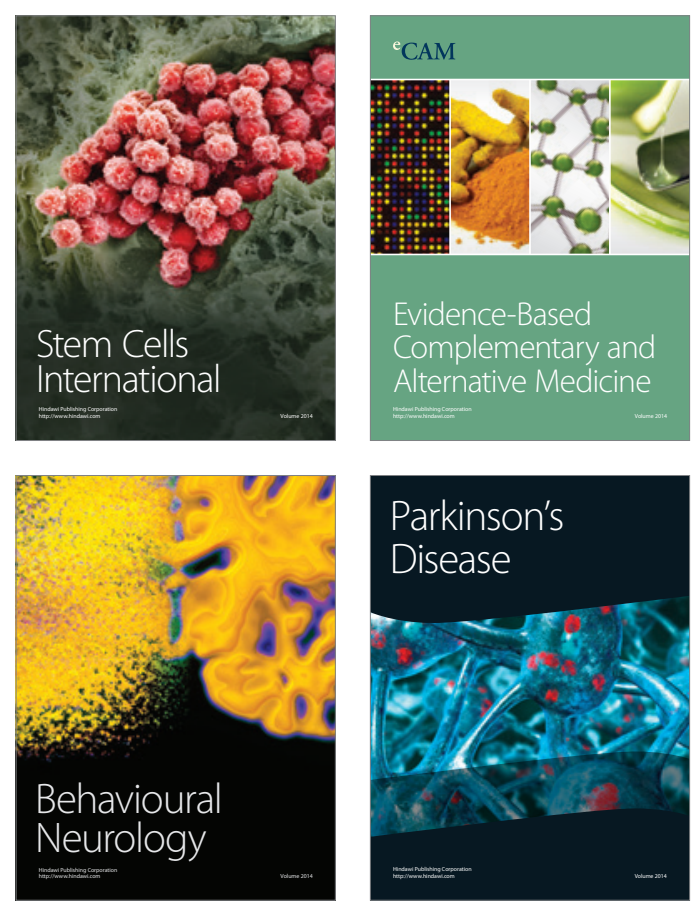

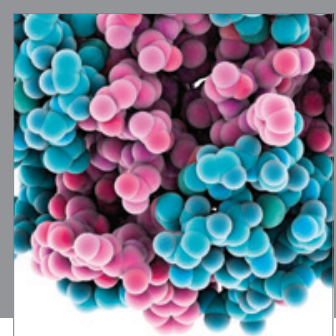

Journal of
Diabetes Research

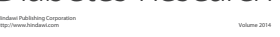

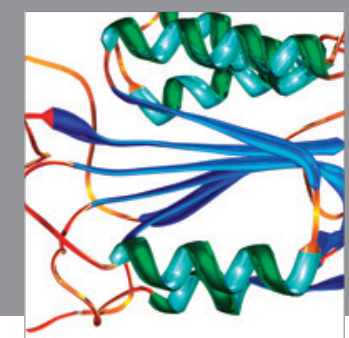

Disease Markers
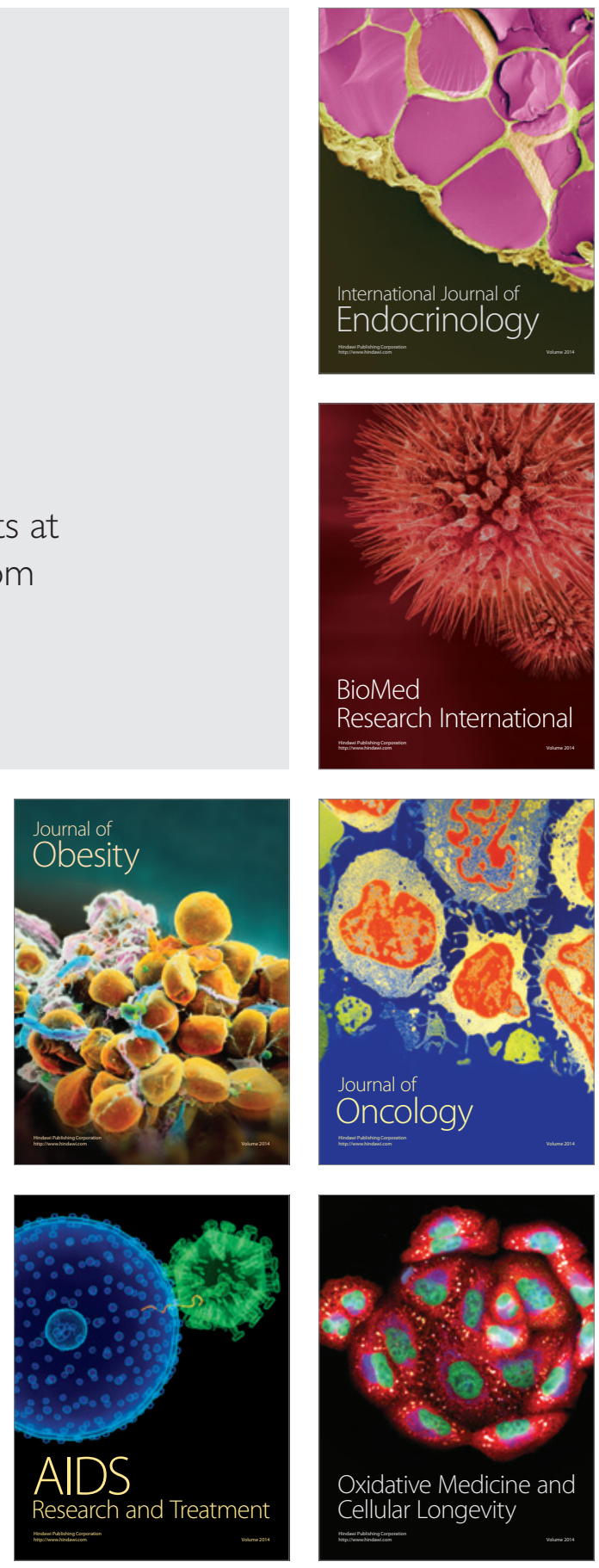